\title{
CLIMA E COTIDIANO: SENSITIVIDADE AOS TIPOS DE TEMPO NA ESCOLA
}

\author{
Climate and routine: sensitivity to weather types in school
}

Clima y diario: sensibilidad a los tipos de tempo en la escuela

\begin{abstract}
Vandirene Drehmer* Bianca Marques Maio** Erika Collischonn***

*Mestranda, Programa de Pós- Graduação em Geografia. Universidade Federal de Pelotasvaldirenedrehmer@hotmail.com. ** Doutoranda, Programa de Pós- Graduação em Geografia. Universidade Federal de Santa Mariabiankamaio@hotmail.com. ***Professora Doutora, Programa de Pós- Graduação em Geografia. Universidade Federal de Pelotaserika.collischonn@ufpel.edu.br
\end{abstract}

Recebido em 20/10/2019. Aceito para publicação em 20/10/2019.

Versão online publicada em 10/11/2019 (http://seer.ufrgs.br/paraonde)

\begin{abstract}
Resumo:
Uma das facetas dos estudo de percepção climática diz respeito ao entendimento das reações psico-fisiológicas das pessoas à condições atmosféricas específicas. Durante o estágio supervisionado no ensino fundamental, etapa da formação de professores é preciso, por norma, realizar observações sobre o comportamento dosalunos em sala de aula. Neste trabalho, estas observaçõesforam organizadas em planilhas e,subsequentemente também foramlevantados dados a respeito dos estados momentâneos da atmosfera do dia em que foram feitas. Posteriormente, foram analisadas cartas sinóticas e imagens de satélite com o objetivo de definir o sistema atmosférico (massa de ar ou perturbação) atuante em cada um desses dias, para definir o tipo de tempo. Em relação aos tipos de tempo, foi utilizada a categorização de SARTORI (2016), que estabelece quinze tipos de tempo reunidos em três grandes famílias, associadas aos dois grandes grupos de sistemas atmosféricos que influenciam a fachada atlântica da América do Sul, principalmente no Rio Grande do Sul.O objetivo foi observar os alunos no intuito de verificar se há padrões específicos de comportamento em sala de aula conforme o tipo de tempo. Conclui-se que vários fatores além do tipo de tempo concorrem para os estados de ânimo e disposição para o estudo em sala de aula (horário da aula, atividade a ser realizada), mas há tipos de tempo que deixaram os estudantes mais irrequietos, enquanto outros, os deixaram mais calmos.
\end{abstract}

Palavras-chave: Tipo de tempo,Percepção Climática, Ambiência escolar, Cotidiano

\begin{abstract}
:
This paper reports an experiment led during a supervised internship in an elementary school, where, as standard, it is necessary to make observations about the students' behavior in the classroom. It also involves improving approaches to geographic climatology and climate sensitivity. Along with the observations, it was detailed the momentary states of the atmosphere for each day. Subsequently, synoptic charts and meteorological weather images were analyzed in order to define the atmospheric system (air mass or disturbance) acting on each of these days to define the type of weather. Regarding the types of weather, we used the bibliographic reference of SARTORI (2016), the author establishes fifteen types of weather gathered in three large families, associated with two large groups of atmospheric systems that influence the Atlantic facade of South America, mainly in Rio Grande do Sul. The aim was to observe the students in order to verify if there are specific behavioral patterns
\end{abstract}


in the classroom according to the type of weather. It is concluded that several factors besides the type of weather contribute to moods and willingness to study in the classroom (class time, activity to be performed), but there are types of weather that make students more restless while others make them calmer.

Key-words: Weather Type, Climate Perception, School Environment, Routine

\begin{abstract}
Resumen:
Una de las facetas de los estudios de percepción climática se refiere a la comprensión de las reacciones psicofisiológicas de las personas a condiciones atmosféricas específicas. Este artículo informa sobre un experimento realizado durante la pasantía supervisada en la escuela primaria, una etapa de formación docente en la que, por regla general, es necesario hacer observaciones sobre el comportamiento de los estudiantes en el aula. Junto con las observaciones de la clase, se recopilaron os datos meteorológicos de cada día. Posteriormente, se analizaroncartas sinópticas e imágenes satelitales para definir el sistema atmosférico (masa de aire, frente o perturbación) que actuó en cada uno de losdías de observaciones y por lo tanto el tipo de tiempo. Con respecto a los tipos de tiempo, fue utilizada la categorización de SARTORI (2016), que establece quince tipos de tempo reunidos en tres grandes familias, asociadas con dos grandes grupos de sistemas atmosféricos que influyen en la fachada atlántica de América del Sur, principalmente en Río Grande do Sul. El propósito del estudio fue verificar si hay patrones específicos de comportamiento en el aula según el tipo de tiempo. Se concluye que varios factores además del tipo de tiempo contribuyen a los estados de ánimo y la voluntad de estudiar en el aula (tiempo de clase, actividad a realizar), pero hay tipos de tiempo que hacen que los estudiantes estén más inquietos mientras otros los hacen más tranquilos.
\end{abstract}

Palabras-clave:Tipo de tiempo, percepción del clima, ambiente escolar, vida cotidiana

\title{
1 Introdução
}

No cotidiano da escola há uma riqueza de aspectos a serem estudados sobre a relação dos estudantes com o ambiente em que vivem. Cada lugar tem características que se relacionam, ora a espaços regionais mais amplos, ora ao espaço mais restrito do seu entorno. Além disso cada lugar é marcado por suas temporalidades.

Incentivar a percepção destas diferenças espaciais e temporais interagindo sobre 0 lugar é uma das tarefas fundamentais do professor de geografia. Incentivar a percepção do contexto climático em que um lugar se insere, é uma das vias de desenvolver estas noções escalares com os alunos.

Para fazê-lo Sartori (2016) propõe que se inicie na escola observando a sensitividade ao tempo e ao clima. Para a autora este conceito diz respeito a forma como o clima e os tipos tempo exercem influência na vida das pessoas, essa percepção se manifesta na vida cotidiana dos indivíduos. Tem a ver com a constituição do ser humano, seus hábitos e o ambiente em que vive, que definem situações de bem-estar ou mal-estar no seu cotidiano. Cada lugar tem características geográficas que podem potencializar as percepções climáticas.

A tempo-sensitividade é um "estímulo subliminar", ou seja, é um estímulo que, às vezes, não tem intensidade suficiente para que a pessoa tenha consciência e identifique-o, mas se for repetido pode desenvolver uma gradativa sensitividade e, assim, acaba por induzir efeitos psicofisiológicos. É uma resposta humana, uma adaptação ao estresse, estímulo ou excitação de uma atmosfera constantemente

ParaOnde!?, Porto Alegre, v.12 n.2, p.226-237, 2019.http://seer.ufrgs.br/paraonde Edição Especial - III Colóquio de Pesquisadores em Geografia Física Ensino de Geografia 
mutante. Os homens são provocados por mudanças na umidade, na temperatura, na insolação, no tempo de forma geral. Há muitos paradoxos quanto à temposensitividade humana, pois não é propriamente uma doença, mas indicadora de saúde física geral, mental ou emocional(SARTORI, p.104, 2014).

O termo tempo-sensitividade se refere às reações induzidas pelos tipos de tempo que são externalizadas por algumas pessoas. Tais reações não são iguais em todas as pessoas, cada um tem sua forma de agir e reagir em resposta aos tipos de tempo, unssão mais tempo-sensitivosque os outros. Conforme Sartori (2014, p. 105),"o estudo clínico das perturbações ligadas à variabilidade dos tipos de tempo indica que certas pessoas são pouco sensíveis a estas variações, enquanto outros apresentam sensibilidade muito grande, com todos os intermediários possíveis".

Sartori (2014) ainda destaca que em alguns momentos de mudanças em elementos como umidade, temperatura,insolação, precipitação, radiação solar, insolação, ventos, nevoeiro, ou no tempo como um todo, podem alterar o comportamento de bemestar de pessoas que são mais tempo-sensitivas, enquanto outras não demostram reação alguma. E pode-se citar alguns sintomas de pessoas tempo-sensitivas como: cansaço, nervosismo, indiferença, pressão na cabeça, nervosismo, sono intranquilo ou interrompido, dificuldades de dormir, dor nas fraturas, sonolência, aumento na tendência de cometer erros, esquecimento, tontura, dores em cicatrizes.

Da mesma forma, Alves (2011), relata que o sistema termorregulador é diferente para as pessoas dependendo do seu entranhamento com o seuespaço vivido. Alguns sentem reações no organismos quando ocorrem variações no tempo meteorológico, devido às reações do organismo, resultando em indisposição ou disposição.

O aspecto subjetivo deve ser lembrado aqui, pois cada indivíduo reage de uma forma às condições de tempo. Alguns são mais tolerantes aos rigores do frio e calor, dependendo do grau de aclimatação. Para o habitante de uma zona temperada do globo, como o Canadá, a temperatura de $15^{\circ} \mathrm{C}$ pode ser considerada razoável e confortável, ao contrário de um morador do semiárido nordestino brasileiro, acostumado com temperaturas elevadas. Certamente este sofreria com a temperatura mencionada (ALVES, 2011, p. 21).

Sartori (2014) considera que o ser humano tem uma forma de se adaptar pelo sistema de regulação. Mas as capacidades fisiológicas do organismo de adaptação são melhores para o calor, pois, por meio do suor a pele resfria e o organismo se autorregula, já para se proteger do frio não há autorregulação, é preciso agasalhar-se. Mas o organismo humano busca sempre uma forma adaptativa para enfrentar as mudanças de tempo, que muitas vezes transparecem na forma como as pessoas se comportam no seu cotidiano e respondem com disposição ou indisposição. E na maioria das vezes as pessoas não tem consciência deste estimulo subliminar que, ao se repetir, pode gerar uma sensitividade e gerar efeitos psicofisiológicos. Assim, por exemplo, reações psicofisiológicas podem ser induzidas pelo tipo de tempo que ocorre em certo dia, ou já se mostram nos dias anteriores a um tipo de tempo específico (SARTORI, 2014, p. 104).

A concepção de clima através do qual Sartori $(2014,2016)$ desenvolveu sua pesquisa não é o de estado médio da atmosfera por um período de 30 anos de dados, mas sim, o de sucessão dos tipos de tempo, seus padrões e suas exceções, ou seja, um conceito mais próximo do dia a dia. O ritmo dessa sucessão depende, basicamente, da

ParaOnde!?, Porto Alegre, v.12 n.2, p.226-237, 2019.http://seer.ufrgs.br/paraonde Edição Especial - III Colóquio de Pesquisadores em Geografia Física Ensino de Geografia 
atuação dos fluxos atmosféricos, os quais, por sua vez, são determinados por centros de pressão, revelando assim, a gênese dos fenômenos climáticos (CARACRISTI, 2002). A sucessão dos tipos de tempo traz consigo confortos e desconfortos que contribuem ou não na disposição das pessoas à determinadas atividades.

Este artigoé parte do que seapresentou em Monografia de Conclusão de Curso. Relata-se um experimento realizado durante o estágio do ensino fundamental que procurou avaliar a relação entre tipo de tempo e disposição em sala de aula, tanto a expressa pelos alunos quanto a percebida pela estagiária.

\section{Metodologia}

Primeiramente foi construído um referencial teórico a respeito da temática sensitividade climática e tipo de tempo, para o qual Sartori (2016) foi a autora fundamental.

As observações sobre os estudantes em sala de aula, para averiguar seu comportamento diário, foram realizadas em dois períodos no estágio do curso de Licenciatura em Geografia da Universidade Federal de Pelotas: a primeira, com menos interação, foi durante o período de acompanhamento e observação da turma, ainda sob a professora regente, no mês de setembro de 2017; a segunda foi realizadanos meses seguintes, já como professora estagiária. A turma era de $7^{\circ}$ ano numa escola municipal de Pelotas e o estágio ocorreu de 25 de setembro de 2017 a 15 de dezembro de 2017. A percepção da estagiária e as respostas escritas pelos alunos foram organizados conforme o dia.

Numa segunda parte da pesquisa foi fundamental a interpretação da carta sinótica dos dias de interação com a turma, assim como dos dias imediatamente anterior e posterior, com o objetivo de identificar o tipo de tempo que fazia. A Marinha do Brasil disponibiliza na sua página na rede internet, duas cartas sinóticas diárias pela hora universal: Oh que corresponde as $21 \mathrm{~h}$ do dia anterior e $12 \mathrm{~h}$, que corresponde as $9 \mathrm{~h}$ da manhã para o fuso -3 e $10 \mathrm{~h}$ da manhã em situação de horário de verão. Para auxiliar na interpretação foram utilizadas também imagens do canal IR do Satélite GOES tratadas em tons de cinza, obtidas no sítio do Instituto de Pesquisas Espaciais na Internet (http//www.inpe.com.br).

Em relação ao tipos de tempo, para o Rio Grande do Sul, Sartori (2016) conseguiu identificar quinze tipos de tempo, reunidos em três grandes famílias, associadas aos dois grandes grupos de sistemas atmosféricos que influenciam a fachada atlântica da América do Sul. São eles: 1. Sistemas extratropicais, com seus mecanismos frontais, instabilizadores do tempo (FPA), e seus domínios anticiclonais polares de ações estabilizadoras MPA (Massa Polar Atlântica) e MPV (Massa Polar Velha); 2. Sistemas intertropicais, com seus domínios tropicais marítimos MTA (Massa Tropical Atlântica) estabilizadores do tempo e suas correntes tropicais continentais MTC (Massa Tropical Continental) com fluxos de oeste e noroeste, responsáveis por fortes aquecimentos préfrontais instablizadores do tempo, antes de passagens frontais (SARTORI, 2016, p.51).

Os tipos de tempo são respostas dadas pelos elementos meteorológicos, ao domínio ou avanço desses sistemas atmosféricos. Cada tipo de tempo tem uma característica que o define, segundo a massa de ar ou sistema perturbado atuante. Por

ParaOnde!?, Porto Alegre, v.12 n.2, p.226-237, 2019.http://seer.ufrgs.br/paraonde

Edição Especial - III Colóquio de Pesquisadores em Geografia Física Ensino de Geografia 
não existir uma terminologia climatológica consagrada nacionalmente, Sartori (2016, p. 52-70) definiu uma nomenclatura própria para cada tipo de tempo, segundo três grandes famílias:

1 Tempos anticiclonais polares: Tempo anticiclonal polar típico, Tempo anticiclônico polar marítimo, Tempo anticiclônico polar pós-frontal, tempo anticiclônico polar continental, tempo anticiclônico polar em tropicalização, tempo anticiclonal aquecido.

2. Tempos associados a sistemas intertropicais: anticiclônico tropical marítimo, anticiclônico tropical continentalizado, tempo depressionário continental.

3. Tempos associados a correntes perturbadas: Tempo frontal de sudoeste de ação moderada, tempo frontal de sudoeste de fraca atuação, Tempo frontal estacionário, Tempo frontal de nordeste, Tempo frontal ciclonal de ação direta, Tempo frontal ciclonal de ação indireta.

\section{Resultados}

A pesquisa de campo foi realizada numa Escola Municipal, localizada no bairro Fragata, na cidade de Pelotas/RS. A turma na qual se realizou o estágio do Ensino Fundamental era composta de 22 alunos entre 12 e 14 anos, dos quais 14 eram meninos e 8 eram meninas. Apenas os dois meninos repetentes já tinham 14 anos completos, havia também um aluno com laudo médico de déficit de atenção e três meninos e três meninas obesos. Pode notar-se que um menino faltava muito a aula; o mesmo, segundo a professora, havia perdido o pai no ano anterior, talvez por isso não mostrava entusiasmo, era tímido e não entregava os trabalhos. Outro menino que tinha déficit de atenção também havia perdido o pai recentemente e vivia com a avó.

Ao todo, durante o estágio, foram realizados 19 encontros. Na sequência são apresentados três exemplos de resultados de dias de atividades em classe: 5 de outubro, 11 de outubro e $1^{\circ}$ de novembro, todos no ano de 2017. Primeiramente, apresentam-se as características do dia em termos de tempo meteorológico e, posteriormente, são apresentadas as características da turma para este dia.

Na carta sinótica (figura 1) de superfície das $12 Z$ do dia 05 de outubro de 2017, há uma frente fria estendida desde o sudoeste da Província de Santa Fé na Argentina, que pela calha do Rio da Prata segue pelo Atlântico até uma baixa pressão relativa de 988 $\mathrm{hPa}$, localizada em $47^{\circ} \mathrm{S} / 53^{\circ} \mathrm{W}$. Uma alta pressão pós-frontal tem valor de $1006 \mathrm{hPa}$ nas Províncias de La Pampa, San Luís e de Córdoba. Outra frente fria atua na Patagônia Argentina e se estende em direção a Terra do Fogo e ao Estreito de Drake, onde oclui com pressão de $952 \mathrm{hPa}$. Um cavado está estendido entre o extremo sul da Província de Mendoza ao sudeste da Província de Chubut na Argentina.

ParaOnde!?, Porto Alegre, v.12 n.2, p.226-237, 2019.http://seer.ufrgs.br/paraonde Edição Especial - III Colóquio de Pesquisadores em Geografia Física Ensino de Geografia 
Figura 1- Carta Sinótica, dia 05 de outubro de 2017

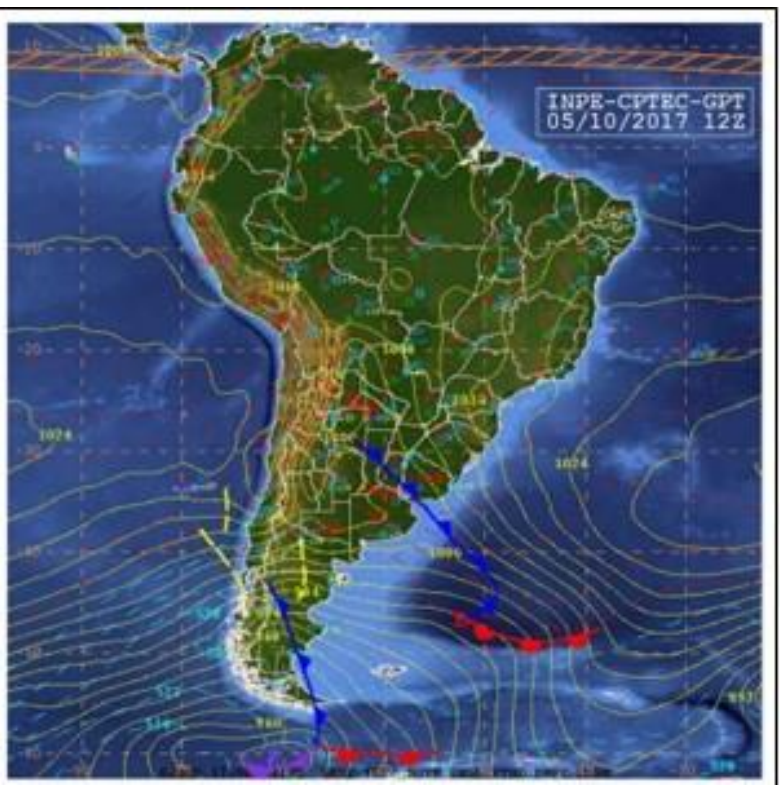

Fonte: CPTEC/INPE, 2017 e INMET, 2018.

\section{Características do tempo meteorológico dia 05 de outubro de 2017:}

Foi um dia com temperatura: média $22,0^{\circ} \mathrm{C}$ máxima $30,4^{\circ} \mathrm{C}$ mínima $15,1^{\circ} \mathrm{C}$ Umidade relativa: $62,1 \%$

Vento: Média $8,4 \mathrm{Km} / \mathrm{h}$ e Máxima 27,4 $\mathrm{Km} / \mathrm{h}$

Direção do Vento: $\mathrm{NE}$

Chuva: $0,0 \mathrm{~mm}$

Pressão atmosférica: $1007,6 \mathrm{hPa}$

O tipo de tempo registrado nesse dia, segundo a Classificação de Sartori (2016) foi o tempo anticiclônico polar em tropicalização. Esse tempo está ligado ao domínio da Massa Polar Velha (MPV), registrando aumento das temperaturas máximas $\left(>25^{\circ} \mathrm{C}\right)$ e mínimas de no mínimo $15^{\circ} \mathrm{C}$, com grande amplitude térmica. Quando em fase pré-frontal, como é o caso nesse dia, podem ocorrer chuvas provocadas por instabilidades Tropicais e Calhas induzidas. Esse é a condição atmosférica em que se define o Vento Norte (SARTORI, 2016, p. 56).

No dia 05 de outubrofoi difícil trabalhar pois a turma estava dispersa e agitada. $\mathrm{O}$ tempo de contato com a turma também foi curto, das $11 \mathrm{~h} 00 \mathrm{~min}$ até as $11 \mathrm{~h} 30 \mathrm{~min} .0$ comportamento da turma poderia esta relacionadoao fato se ser final da manhã e porque tinham vindo do recreio. Algumas meninas no fundo da aula brincavam com as mãos (alguma brincadeira adolescente) e faziam algazarra e os estudantes, no geral, levantavam muito e caminhavam na sala. Alguns chamavam a atenção para dialogar, mas demonstravam claramente pressa de ir-se embora. Nesta aula foi possível fazer algumas perguntas e apresentar uma sequência de imagens e textos sobre a cultura Nordestina e, mesmo com a agitação, aindahouve interação. A turma não foi desrespeitosa com a estagiária, não ficou testando, mas houve muita agitação e conversa demasiada.

$\mathrm{Na}$ carta sinótica das $12 \mathrm{Z}$ do dia 11 de outubro de 2017 (figura 2), observa-se um sistema frontal com ramo estacionário entre a Argentina e RS, prolongando-se como frente fria sobre o Oceano Atlântico a leste de $40^{\circ} \mathrm{W}$, até uma baixa pressão no valor de $956 \mathrm{hPa}$, localizada em torno de $53^{\circ} \mathrm{S} / 29^{\circ} \mathrm{W}$. Sobre o Estreito de Drake, observa-se uma frente fria próximo do extremo sul do continente. Então Pelotas, segundo interpretação baseada em Sartori (2003), estava sob Tempo Frontal Estacionário.

ParaOnde!?, Porto Alegre, v.12 n.2, p.226-237, 2019.http://seer.ufrgs.br/paraonde Edição Especial - III Colóquio de Pesquisadores em Geografia Física Ensino de Geografia 
Figura 2- Carta Sinótica, dia 11 de outubro de 2017

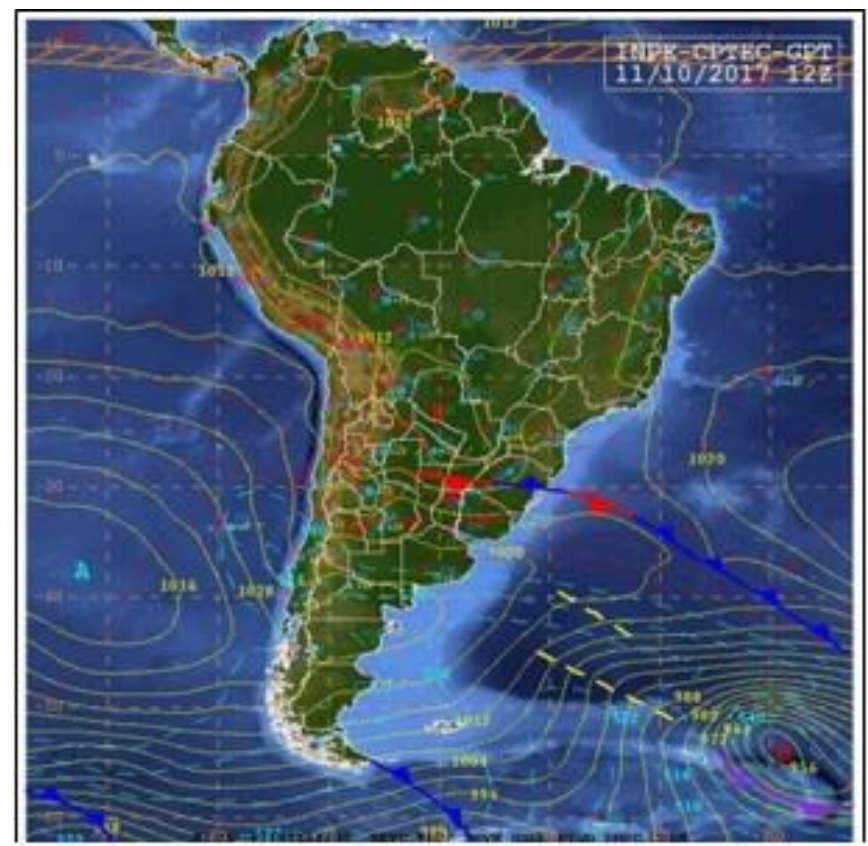

Características do tempo meteor. dia 11 de outubro de 2017:

Foi um dia com temperatura: média $16,3^{\circ}$ máxima $17,4^{\circ}$ mínima $15,3^{\circ}$

Umidade relativa: $88,8 \%$

Vento: média $9,2 \mathrm{Km} / \mathrm{h}$, Máxima 29,0 $\mathrm{Km} / \mathrm{h}$

Direção do Vento: $E$

Chuva: $8,8 \mathrm{~mm}$

Pressão atmosférica: $1015 \mathrm{hPa}$

Fonte: CPTEC/INPE, 2017 e INMET, 2018.

No dia 11 de outubroo período de aula era cedo pela manhã, das 7h30min às 8h50min. Neste dia, os alunos estavam calmos e interagiram mais. Alguns mais quietos e outros mais falantes, estava um pouco frio e chovia em alguns momentos. Mas apesar de alguns conversarem a grande maioria estava quieta. Não pareciam cansados, pareciam dispostos e atentos a aula. Nesta turma, sempre foi necessário manter o foco, pois os estudantes se distraíam com facilidade. Mas apesar de estar chuvoso e frio o dia não estava cansativo favorecendo a interação com eles.

Na carta sinótica (figura 3) das $12 Z$ do dia 01 de novembro de 2017, observa-se um ramo estacionário no $\mathrm{ES}$, prologando-se pelo Atlântico com ramo frio até o centro de baixa pressão de $992 \mathrm{hPa}$ em torno de $38^{\circ} \mathrm{S} / 32^{\circ} \mathrm{W}$. Outro sistema frontal transiente é observado no Atlântico, ao sul do sistema frontal mencionada. A alta pressão pós-frontal atua com núcleo no valor de $1020 \mathrm{hPa}$ em torno de $37^{\circ} \mathrm{S} / 55^{\circ} \mathrm{W}$. No centro-nordeste do Brasil, está traçada uma Zona de Convergência de Umidade (ZCOU) atuando entre o sul do PA e o oceano Atlântico, onde se acopla ao sistema frontal.

Então em Pelotas, segundo interpretação baseada em Sartori (2003), o tempo era do tipo Tempo Anticiclonal Aquecido, céu limpo, ventos leves e calmas, com grande amplitude térmica pelo aumento das temperaturas máximas e declínio das mínimas.

ParaOnde!?, Porto Alegre, v.12 n.2, p.226-237, 2019.http://seer.ufrgs.br/paraonde Edição Especial - III Colóquio de Pesquisadores em Geografia Física Ensino de Geografia 
Figura 3- Carta Sinótica, dia 1ำ de novembro de 2017

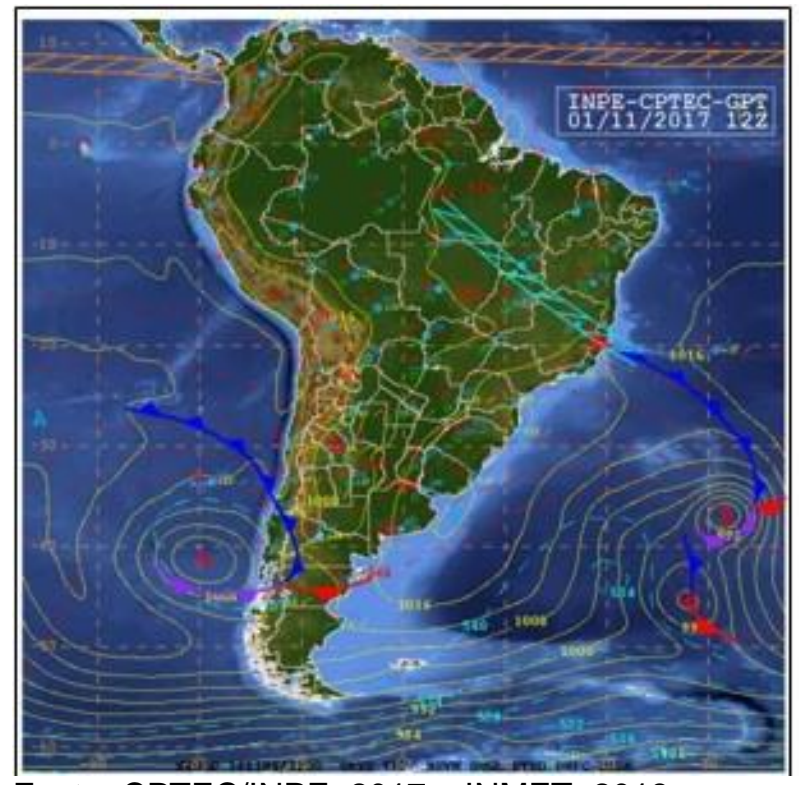

Características do tempo meteor. dia $1^{\circ}$ de novembro de 2017:

Foi um dia com temperatura: média $17,8^{\circ} \mathrm{C}$ máxima $24,4^{\circ} \mathrm{C}$ mínima $10,9^{\circ} \mathrm{C}$ Umidade relativa: $63,5 \%$

Vento: Média 4,6 Km/h e Máxima 25,7 $\mathrm{Km} / \mathrm{h}$

Direção do Vento: SW

Chuva: $0,0 \mathrm{~mm}$

Pressão atmosférica: $1018 \mathrm{hPa}$

Fonte: CPTEC/INPE, 2017 e INMET, 2018

Normalmente, as aulas na quarta-feira, como esse $1^{\circ}$ de novembro, eram animadas; os alunos sempre recebiam com bom dia, tudo bem, alguns até abraçavam. Neste dia, estavam aparentemente tranquilos mas havia alguns no fundo da sala que conversavam muito. Não tinham aparência de cansados, só não participaram da aula. Normalmente participavam mais. Duas meninas perguntaram sobre o que é fabricado a partir de petróleo, o restante estava disperso. A turma sempre era normalmente de conversa, mas participativa. Neste, porém, estavam dispersos e desatentos. Acredita-se que, mais do que o tipo de tempo, estavam já em ritmo de feriadão de finados. Foi aplicada uma prova e terminaram rápido porque queriam logo saber a nota.

Esta foi a forma como foram organizados, inicialmente, os dados de todos os 19 encontros. Esta organização permitiu a definição de um quadro síntese contendo ostipo de tempo e a ambiência da turma em todos os encontros do período do estágio(Quadro 1).

Do quadro algumas informações podem ser lidas. O tipo de tempo em que, mais frequentemente, os alunos se mostraram agitados foi o tempo anticiclônico polar em tropicalização, principalmente, quando as aulas de geografia ocorriam no final da manhã (11-11h30min). Já quando a aula ocorria às $7 \mathrm{~h} 30 \mathrm{~min}$ da manhã, em geral, se mostraram mais calmos, a exceção do primeiro dia de observação, que foi um dia de tempo anticiclônico polar em tropicalização, quando estiveram dispersos e desatentos e conversavam muito. Neste primeiro diaos alunos tambémdeveriam estar testando a estagiária.

ParaOnde!?, Porto Alegre, v.12 n.2, p.226-237, 2019.http://seer.ufrgs.br/paraonde Edição Especial - III Colóquio de Pesquisadores em Geografia Física Ensino de Geografia 


\section{Quadro 1- Síntese entre tipo de tempo e ambiência da turma nos dias de estágio}

\begin{tabular}{|c|c|c|c|c|c|c|}
\hline Dia/Mês & $\begin{array}{l}\text { Pressão } \\
\text { Atmosférica } \\
\text { /Ventos }\end{array}$ & $\begin{array}{c}\text { Sistema } \\
\text { atmosférico }\end{array}$ & Tipo de Tempo & Horário & Atividades & Comportamento \\
\hline $25 /$ set & 1019.2hPa, NE, & MPV & $\begin{array}{l}\text { Tempo anticiclônico } \\
\text { polar em tropicalização }\end{array}$ & $7 \mathrm{~h} 30 \mathrm{~min}$ às $10 \mathrm{~h}$ & Observação & $\begin{array}{c}\text { Muita conversa, dispersos e } \\
\text { desatentos }\end{array}$ \\
\hline 04/out & $1010 \mathrm{hPa}, \mathrm{NE}$ & MPV & $\begin{array}{l}\text { Tempo anticiclônico } \\
\text { polar em tropicalização }\end{array}$ & $7 \mathrm{~h} 30 \mathrm{~min}$ às $9 \mathrm{~h}$ & $\begin{array}{l}\text { Apresentação da } \\
\text { estagiária }\end{array}$ & $\begin{array}{c}\text { Estavam curiosos e } \\
\text { participaram }\end{array}$ \\
\hline 05/out & 1007.6hPa, NE & MPV & $\begin{array}{l}\text { Tempo anticiclônico } \\
\text { polar em tropicalização }\end{array}$ & $11 \mathrm{~h}$ às $11 \mathrm{~h} 30 \mathrm{~min}$ & Regiões brasileiras & Dispersos e agitados \\
\hline 11/out & 1015hPa, E & FPA & $\begin{array}{l}\text { Tempo frontal } \\
\text { estacionário }\end{array}$ & $7 \mathrm{~h} 30 \mathrm{~min}$ às $9 \mathrm{~h}$ & Regiões brasileiras & $\begin{array}{c}\text { Estavam calmos e } \\
\text { interagiam mais dia frio e } \\
\text { chuvoso }\end{array}$ \\
\hline 18/out & $1009 \mathrm{hPa}, \mathrm{S}$ & MTA & $\begin{array}{l}\text { Tempo anticiclônico } \\
\text { tropical marítimo }\end{array}$ & $7 \mathrm{~h} 30 \mathrm{~min}$ às $9 \mathrm{~h}$ & Regiões brasileiras & $\begin{array}{c}\text { Dia } 15 \text { horário de verão, } \\
\text { cansados, entediados e } \\
\text { lentos }\end{array}$ \\
\hline 25/out & 1013.9hPa, NE & MPV & $\begin{array}{l}\text { Tempo anticiclônico } \\
\text { polar em tropicalização }\end{array}$ & $7 \mathrm{~h} 30 \mathrm{~min}$ às $9 \mathrm{~h}$ & Prova & $\begin{array}{l}\text { Bem dispostos e alegres, } \\
\text { sempre conversam um } \\
\text { pouco }\end{array}$ \\
\hline 26/out & $1010,2 \mathrm{hPa}, \mathrm{NE}$ & MPV & $\begin{array}{l}\text { Tempo anticiclônico } \\
\text { polar em tropicalização }\end{array}$ & $11 \mathrm{~h}$ às $11 \mathrm{~h} 30 \mathrm{~min}$ & Atividade com bússola & $\begin{array}{c}\text { Fomos para o pátio mas } \\
\text { poucos participaram, } \\
\text { agitados }\end{array}$ \\
\hline 01/nov & 1018hPa, SW & MPV & $\begin{array}{c}\text { Tempo Anticiclonal } \\
\text { Aquecido }\end{array}$ & $7 \mathrm{~h} 30 \mathrm{~min}$ às $9 \mathrm{~h}$ & Regiões brasileiras & $\begin{array}{c}\text { Dispersos e desatentos, } \\
\text { sem aparência de cansados }\end{array}$ \\
\hline 08/nov & $1011 \mathrm{hPa}, \mathrm{NE}$ & MPV & $\begin{array}{l}\text { Tempo anticiclônico } \\
\text { polar em tropicalização }\end{array}$ & $7 \mathrm{~h} 30 \mathrm{~min}$ às $9 \mathrm{~h}$ & Regiões brasileiras & $\begin{array}{l}\text { Estavam tranquilos e } \\
\text { atentos, mas um meninos } \\
\text { agitado }\end{array}$ \\
\hline 09/nov & 1009.6hPa, N & MPV & $\begin{array}{l}\text { Tempo anticiclônico } \\
\text { polar em tropicalização }\end{array}$ & $11 \mathrm{~h}$ às $11 \mathrm{~h} 30 \mathrm{~min}$ & Atividade com Mapa & $\begin{array}{c}\text { Agitados e bagunçando foi } \\
\text { difícil }\end{array}$ \\
\hline $16 /$ nov & 1010.6hPa,SW & FPA & $\begin{array}{c}\text { Frontal de Sudoeste de } \\
\text { Fraca Atuação }\end{array}$ & $11 \mathrm{~h}$ às $11 \mathrm{~h} 30 \mathrm{~min}$ & Regiões brasileiras & $\begin{array}{c}\text { Pós feriado, a maioria de pé } \\
\text { agitados e bagunçando }\end{array}$ \\
\hline 22/nov & 1014.3hPa,SW & MPA & $\begin{array}{c}\text { Tempo anticiclônico pós- } \\
\text { frontal }\end{array}$ & $7 \mathrm{~h} 30 \mathrm{~min}$ às $9 \mathrm{~h}$ & $\begin{array}{l}\text { Apresentação de } \\
\text { trabalho }\end{array}$ & $\begin{array}{l}\text { Estavam calmos, as vezes } \\
\text { alguns conversavam }\end{array}$ \\
\hline 23/nov & $1011 \mathrm{hPa}, \mathrm{NW}$ & MPV & $\begin{array}{l}\text { Tempo anticiclônico } \\
\text { polar em tropicalização }\end{array}$ & $11 \mathrm{~h}$ às $11 \mathrm{~h} 30 \mathrm{~min}$ & $\begin{array}{l}\text { Apresentação de } \\
\text { trabalho }\end{array}$ & $\begin{array}{c}\text { Agitados e bagunçando, } \\
\text { difícil terminar as } \\
\text { apresentações }\end{array}$ \\
\hline 29/nov & 1017.2hPa, E & MPV & $\begin{array}{c}\text { Tempo anticiclônico } \\
\text { polar em tropicalização }\end{array}$ & $7 \mathrm{~h} 30 \mathrm{~min}$ às $9 \mathrm{~h}$ & Finalizar conteúdo & $\begin{array}{c}\text { Conversavam bastante mas } \\
\text { participavam da aula }\end{array}$ \\
\hline $30 /$ nov & 1013.5hPa, NE & MTA & $\begin{array}{l}\text { Tempo anticiclônico } \\
\text { tropical márítimo }\end{array}$ & $11 \mathrm{~h}$ às $11 \mathrm{~h} 30 \mathrm{~min}$ & Oficina Empatia & $\begin{array}{c}\text { Não deu muito certo, mas } \\
\text { não estavam muito agitados }\end{array}$ \\
\hline 06/dez & 1013hPa, NE & MPV & $\begin{array}{l}\text { Tempo anticiclônico } \\
\text { polar em tropicalização }\end{array}$ & $7 \mathrm{~h} 30 \mathrm{~min}$ às $9 \mathrm{~h}$ & $\begin{array}{l}\text { Notas trimestre e } \\
\text { revisão }\end{array}$ & $\begin{array}{l}\text { Calmos mas ansiosos, as } \\
\text { vezes conversavam. Dia } \\
\text { chuvoso }\end{array}$ \\
\hline 07/dez & 1006.7hPa, SW & MTA & $\begin{array}{l}\text { Tempo anticiclônico } \\
\text { tropical marítimo }\end{array}$ & $11 \mathrm{~h}$ às $11 \mathrm{~h} 30 \mathrm{~min}$ & Correção da revisão & $\begin{array}{c}\text { Calmos e as vezes } \\
\text { conversavam }\end{array}$ \\
\hline $14 / \mathrm{dez}$ & 1008.3hPa, N & MTA & $\begin{array}{l}\text { Tempo anticiclônico } \\
\text { tropical marítimo }\end{array}$ & $8 \mathrm{~h}$ às $10 \mathrm{~h}$ & $\begin{array}{c}\text { Plantão para tirar } \\
\text { dúvidas }\end{array}$ & Só um estudante foi \\
\hline 15/dez & 1012.2hPa, NE & MTA & $\begin{array}{l}\text { Tempo anticiclônico } \\
\text { tropical marítimo }\end{array}$ & $8 \mathrm{~h}$ às $10 \mathrm{~h}$ & Recuperação & $\begin{array}{l}7 \text { estudantes, estavam } \\
\text { calmos. Estava calor }\end{array}$ \\
\hline
\end{tabular}

Fonte: Organização da autora (2018).

Como já mencionado, o estágio ocorreu do mês de setembro a mês de dezembro de 2017, portanto,um período transicional entre a estações fria e quente no sul do Brasil. Para a primavera,Sartori (2016) em suas pesquisas na região central do estado do Rio Grande do Sul, constatou que:

Devido ao gradativo aquecimento continental na primavera (22 de setembro a 21 de dezembro) em todo território brasileiro, a Massa Polar Atlântica perde sua liderança na frequência para a Massa Polar Velha, pois embora sendo época transicional, como o outono, a participação do ar polar tropicalizado é bem maior nesta estação do que naquela. Assim, na maioria das vezes, a MPV domina de 1 a 6 dias após a permanência de 1 a 4 dias de MPA ou logo depois da passagem da frente fria, controlando o tempo na região em cerca de $45 \%$ do total de 90 dias de primavera. Por consequência, verifica-se redução na frequência da Massa Polar 
Atlântica, predominando em cerca de $30 \%$ dos dias, enquanto a FPA mantém sua participação e domina as condições de tempo em $20 \%$ dos dias, em média.(SARTORI, 2016, p. 50 e 51)

A contabilização dos tipos de tempo para os dias de estágio (figura 4), em Pelotas, mostrou distibuição similar ao que foi descrito por Sartori, com uma predominância de ar polar tropicalizado.

Figura 4: Frequencia dos tipos de tempo nos dias de estágio em 2017 na cidade de Pelotas.

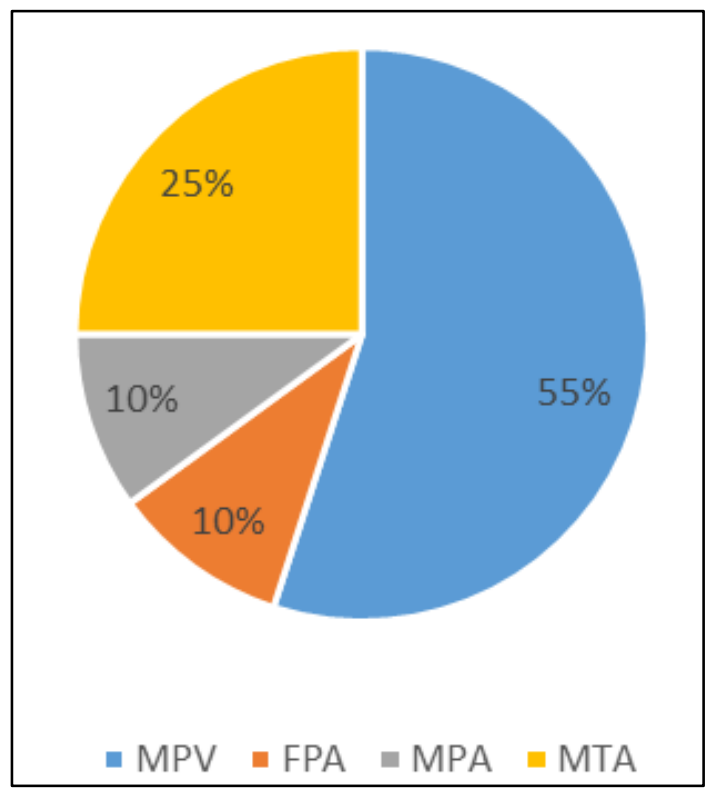

Fonte: Organização das autoras (2018).

\section{Considerações finais}

O que pode se observar nesta pesquisa é que a dinâmica do tempo também influencia no comportamento diário dos estudantes, alguns mais outros menos. Tipos de tempo concorrem para o bem ou mal-estar dos alunos em aula,juntamente com outros fatores como horário da aula, dia da semana, tipo de atividade e situações individuais.

Um fator observado foi que o tipo de tempo anticiclônico polar em tropicalização, foi o que, com maior frequência, alterou o comportamento de alguns adolescentes em sala de aula, principalmente quando as classes de geografia ocorriam no final do turno da manhã. Sartori $(2014,2016)$ em suas pesquisas relata e pode observar e constatar, que mudanças bruscas de temperatura, umidade e ventos alteravam o comportamento dos estudantes. Dias que estavam com baixa pressão os estudantes também demostraram cansaço, desatenção e agitação.

Os dias em que houve uma melhor disposição para o aprendizado foramaqueles com temperatura mais baixa e chuva leve, os estudantes ficaram mais calmos e participativos.Em dias dealta temperatura e alta umidade relativa do ar, quando um sistema frontal estava prestes apassar pela região, os alunos demostraram mais

ParaOnde!?, Porto Alegre, v.12 n.2, p.226-237, 2019.http://seer.ufrgs.br/paraonde Edição Especial - III Colóquio de Pesquisadores em Geografia Física Ensino de Geografia 
inquietação e pouco interesse.

O que se constatou no trato com os alunos,como também já havia observado Sartori (2014), é que a tempo-sensitividade é um fator complementar para compreender o comportamento dos alunos, visto que existem uma série de fatores que influenciam no cotidiano escolar, principalmente o fato de os alunos serem crianças ou adolescentes, períodos da vida em que osfatores fisiológicos, hormonais, sociais e familiares, podem ser potencialidados conforme o tipo de tempo.

Outro fato observado foi que os meninos demostravam ser mais agitados que as meninas, e os que eram mais instáveis emocionalmente demostraram ser mais temposensitivo. Seria leviano afirmar que o tipo de tempo é determinante, ainda que este possa fazer disparar um processo ou uma reação. Para afirmar algo mais contundente sobre a sensitividade ao tempo meteorológico, o levantamento deveria se repetir em diferentes períodos do ano, além deste que foi de finalização de ano letivo; aí simpoderia ser verificarada a preesença ou não de algum padrão.

Este trabalho contribuiupara o entendimentodos tipos de tempo em climatologia e da importância da sistemática na pesquisana educação geográfica. A abordagem contribuiu na compreensão dos conceitos como o de percepção climática com ênfase do temposensitividade, além de articular elementos empíricos e conceituais, concernentes ao conhecimento científico dos processos espaciais, conforme propõe as Diretrizes Curriculares para os Cursos de Geografia.

\section{Referências}

ALVES, Rogério Rozolen. Métodos de avaliação do conforto térmico humano. 2011, p. 124. Trabalho de Graduação Individual (TGI II). Universidade de São Paulo. São Paulo, 2011.

BRASIL. Ministério da Educação. Diretrizes Curriculares Nacionais para os Cursos de Graduação em Filosofia, História e Geografia. Parecer CNE/CES no 492/2001, aprovado em 3 de abril de 2001, publicado no DOU 9/7/2001, Seção 1e, p. 50.

BRASIL. PREVISÃO DO TEMPO (CPTEC). Tempo. Análise sinóticas. Disponível: https://www.cptec.inpe.br/noticias/noticia/129514

CARACRISTI, I. Geografia e representações gráficas: uma breve abordagem crítica e os novos desafios técnico-metodológicos perpassando pela climatologia. Revista Brasileira de Cartografia, $n^{\circ}$ 55, 2002.

CENTRO DE HIDROGRAFIA DA MARINHA. Marinha do Brasil. Cartas sinóticas. Disponível: $\quad$ https://www.marinha.mil.br/chm/dados-do-smm-cartas-sinoticas/cartassinoticas. Acesso em 2017.

DREHMER, V., Clima e Tempo: tempo-sensitividade no ambiente escolar. 2018, 68f. Trabalho de Conclusão de Curso, Instituto de Ciências Humanas, Universidade Federal de Pelotas. Pelotas, 2018.

ParaOnde!?, Porto Alegre, v.12 n.2, p.226-237, 2019.http://seer.ufrgs.br/paraonde Edição Especial - III Colóquio de Pesquisadores em Geografia Física Ensino de Geografia 
INSTITUTO NACIONAL DE METEOROLOGIA (INMET). Banco de Dados Meteorológicos para Ensino e Pesquisa. "Dados da Rede do INMET» 2017. Disponível em: http://www.inmet.gov.br/projetos/rede/pesquisa/inicio.php. Acesso em maio 2018.

SARTORI. Maria da Graça Barros. A dinâmica do clima do Rio Grande do Sul: indução empírica e conhecimento científico. Revista Terra Livre, Ano 19, vol. I, n. 20. São Paulo: jan/jul. 2003. p. 27-49.

SARTORI. Maria da Graça Barros, O vento norte, Santa Maria,Dr Publicidade, 2016. 256 p.

SARTORI. Maria da Graça Barros, Clima e percepção geográfica: Fundamentos teóricos à percepção climática e à bioclimatologia humana, Santa Maria,Pallotti, 2014. 192 p.

UFPEL. EMBRAPA, Boletim Climatológico Mensal. Dados meteorológicos de Pelotas/RS.Disponível: $\quad$ http://agromet.cpact.embrapa.br/online/Current_Monitor.htm Acesso em 2017. 